\title{
UMA ABORDAGEM \\ SOCIOLINGUÍSTICA DA \\ CONCORDÂNCIA NOMINAL \\ DE NÚMERO NO FALAR \\ DOS MORADORES \\ DO MUNICÍPIO DE \\ FONTE BOA \\ (AMAZONAS)
}

UN ENFOQUE SOCIOLINGUÍSTICO DE LA CONCORDANCIA NOMINAL DE NÚMERO EN EL HABLAR DE LOS HABITANTES DEL MUNICIPIO DE FONTE BOA (AMAZONAS)

A SOCIOLINGUISTIC APPROACH TO NOUN AGREEMENT IN NUMBER IN THE ORAL SPEECH OF INHABITANTS OF THE MUNICIPALITY OF FONTE BOA (STATE OF AMAZONAS)

Flávia Santos Martins*

Universidade Federal do Amazonas

Izete Lehmkuhl Coelho**

Universidade Federal de Santa Catarina

RESUMO: Este artigo, à luz da Sociolinguística Variacionista, propõe-se a refletir sobre a variação na concordância nominal de número na fala de dez moradores da cidade de Fonte Boa, um dos nove municípios pertencentes à microrregião do Alto Solimões (AM), a partir de resultados de Martins (2013). Para este estudo foram descritos e analisados 1.356 dados, submetidos ao programa estatístico Goldvarb2001. Desses dados, 754 foram da variante "presença de marcas de plural" (55\% dos dados) e 602 foram da variante "ausência de marcas de plural" (45\% dos dados). Apesar desse baixo índice de concordância nominal, os resultados mostram que a marcação na concordância é favorecida em Fonte Boa pelas mesmas restrições linguísticas de outras regiões

* Doutora em Linguística pela Universidade Federal de Santa Catarina. Professora Adjunta da Universidade Federal do

Amazonas.E-mail:flavinhaingrid@yahoo.com.br.

** Doutora em Linguística pela Universidade Federal de Santa Catarina. Professora Titular da Universidade Federal de SantaCatarina.E-mail: izete.lehmkuhl.coelho@ufsc.br. 
brasileiras. Quanto às variáveis sociais, 'escolaridade’ segue o padrão de comportamento geral, e 'sexo' revela o homem como favorecedor de marcação, um comportamento particularizado (semelhante ao de zonas menos urbanas), de uma localidade em que os papeis de mulheres e homens ainda são conservadores, sendo a mulher menos sensível à variável 'mercado de trabalho'.

PALAVRAS-CHAVE: Sociolinguística. Concordância nominal de número. Fonte Boa (AM). Particularidades e generalizações.

RESUMEN: Este artículo, basado en la Sociolingüística Variacional, propone investigar la variación en la concordancia nominal de número en el habla de diez habitantes de la ciudad de Fonte Boa, uno de los nueve municipios pertenecientes a la microrregión del Alto Solimões (estado de Amazonas), a partir de los resultados de Martins (2013). Para esta investigación se describieron y analizaron 1356 datos, y se procesaron en el programa estadístico Goldvarb 2001. De esos datos, 754 fueron de la variante "presencia de marcas de plural" (55\% de los datos) y 602 fueron de la variante "ausencia de marcas de plural" (45\% de los datos). A pesar del bajo índice de concordancia nominal, los resultados muestran que la marcación en la concordancia se favorece en Fonte Boa por las mismas restricciones lingüísticas de otras regiones brasileñas. En cuanto a las variables sociales, 'escolaridad' sigue el estándar de comportamiento general, y 'sexo' revela al hombre como favorecedor de marcación, un comportamiento particularizado, de una localidad, en que los papeles de mujeres y hombres todavía son conservadores, siendo la mujer menos sensible a la variable 'mercado de trabajo'.

PALABRAS CLAVE: Sociolingüística. Concordancia nominal de número. Fonte Boa (AM). Particularidades y generalizaciones.

ABSTRACT: The present article, based on Variationist Sociolinguistics, aims to investigate number variation in noun agreement in the speech of ten inhabitants of the city of Fonte Boa, one of nine municipalities that integrate the Alto Solimões micro-region (in the state of Amazonas), based on Martins (2013). In this study, 1,356 pieces of data were described, analyzed, and submitted to the Goldvarb 2001 statistical program. 754 pieces (55\% of the data) consisted of the variable "presence of plural markers", while 602 (45\% of the data) were in the variable "absence of plural markers". In spite of the low rate of noun agreement, results show that the plural marking in the agreement is favored in Fonte Boa by the same linguistic restrictions found in other Brazilian regions. Regarding social variables, 'level of education' reflects standard behavior and 'gender' reveals that men favor marking - in which the roles of women and men are still conservative, and women are less sensitive to the 'job market' variable.

KEYWORDS: Sociolinguistics. Nominal number agreement. Fonte Boa (AM). Particularities and generalizations.

\section{INTRODUÇÃO}

Neste artigo, trataremos de um fenômeno morfossintático variável já bastante estudado em algumas regiões do Brasil: a "concordância nominal de número". Desde a década de 1970, têm sido feitas pesquisas que registram a variabilidade sistemática na variação do referido fenômeno (SCHERRE; BRAGA, 1976; SCHERRE, 1988; FERNANDES, 1996; R. CARVALHO, 1997; LOPES, 2001; CAMPOS; RODRIGUES, 2002; BAXTER, 2009; VEIS RIBEIRO, RIBEIRO, LOREGIAN-PENKAL, 2009; SANTOS, 2010; MARTINS, 2010; SILVA, 2011; BRANDÃO, 2011; CASTRO; PEREIRA, 2012, dentre outros). Os resultados dessas investigações mostram que a variável em questão pode ser expressa por duas variantes:

i) ausência de marcas formais/informais de plural em pelo menos um elemento do Sintagma Nominal (doravante $\mathrm{SN}$ ): "aS meninaS

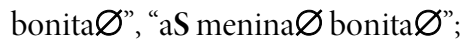

ii) presença de marcas formais/informais de plural em todos os elementos flexionáveis do SN: "aS meninaS bonitaS".

Além disso, os trabalhos mostram que há grupos de fatores linguísticos e extralinguísticos influenciando o uso de uma ou outra variante. Podemos citar como grupos de fatores selecionados, em comum, nas pesquisas realizadas no Brasil, os seguintes: 'posição dos elementos não nucleares em relação ao núcleo/núcleo em relação à posição', 'marcas precedentes', 'saliência fônica', 'escolaridade'e 'sexo'.

No que se refere, especificamente, ao Amazonas, muito pouco foi descrito a respeito deste fenômeno de variação na concordância nominal, havendo, até o momento, apenas dois trabalhos escritos pela mesma pesquisadora - respectivamente, Martins (2010) e 
Martins (2013) ${ }^{1}$ : o primeiro sobre o falar dos moradores do município de Benjamin Constant (pertencente à microrregião do Alto Solimões) com dados do ALAM (Atlas Linguístico do Amazonas); e o segundo relativo ao falar dos moradores do Alto Solimões, a partir de entrevistas individuais realizadas pela própria autora, compondo um banco particular de dados de fala. Em relação ao segundo trabalho, os municípios pertencentes à microrregião estudados por Martins (2013) foram: Fonte Boa, Jutaí, São Paulo de Olivença, Santo Antônio do Içá e Tonantins, ressaltando-se que essa microrregião é composta por nove cidades. Os resultados dessa pesquisa foram apresentados em dois tipos de análises: uma geral (abarcando todas as localidades) e outra por localidades.

O presente trabalho tem como objetivo descrever detalhadamente os resultados encontrados por Martins (2013) em uma dessas localidades, o município de Fonte Boa (AM), apresentando algumas reflexões adicionais sobre os condicionadores internos e externos que atuam na variação da concordância nominal nessa comunidade, com foco nas especificidades da região.

Esta pesquisa está ancorada nos pressupostos teórico-metodológicos da Sociolinguística Variacionista (cf. WEINREICH; LABOV; HERZOG, 2006 [1968]; LABOV, 2008 [1972]; GUY, 2000, dentre outros), observando-se, a priori, a correlação entre fatores internos e externos que condicionam a forma como falantes de determinada comunidade usam a língua em variação. Focalizaremos algumas variáveis linguísticas, que atuam como forças de dentro da língua, e algumas variáveis sociais, que atuam como forças externas, ou de fora da língua, para entendermos um pouco mais sobre o comportamento linguístico dos moradores da cidade de Fonte Boa.

Para esta investigação, consideramos dois dos principais problemas empíricos da Teoria da Variação e Mudança (cf. WEINREICH; LABOV; HERZOG, 2006 [1968]), o problema do encaixamento e o problema de transição, com o propósito de investigar como a variação na concordância nominal está encaixada na estrutura linguística e na estrutura social e como as formas variantes transitam de um lugar a outro, comparando os resultados mais significativos de Fonte Boa, uma localidade menos urbana ${ }^{2}$, com aqueles já encontrados por Martins (2013) nas outras localidades do Alto Solimões e com resultados apresentados por Scherre (1988) e por Fernandes (1996) sobre a fala de outras regiões do Brasil.

Para a análise das variáveis internas que atuam no favorecimento ou desfavorecimento da variação na concordância nominal, controlamos as sete variáveis que se mostraram significativas no trabalho de Martins (2013), como 'posição em relação ao núcleo/núcleo', 'classe gramatical', 'marcas precedentes', 'processos morfofonológicos de formação de plural e tonicidade dos itens lexicais', 'contexto fonético-fonológico subsequente' e 'características dos itens lexicais'. Na busca por explicações de natureza externa, serão retomadas as sete variáveis 'idade', 'escolaridade', 'sexo', 'ocupação', 'diatopia', 'mobilidade' e 'localismo' (redes sociais), pela sua significância em Martins (2013), com o propósito de trazer algumas generalizações sobre os usos linguísticos comuns no falar amazonense (e brasileiro) e específicos da comunidade de Fonte Boa.

A amostra de fala do município de Fonte Boa constitui-se de entrevistas gravadas com 10 informantes, distribuídos de acordo com os fatores sociais 'sexo', 'escolaridade' (8 a 9 anos de escolarização e 9 a 11 anos de escolarização) e 'idade' (18 a 35, 36 a 55 e 56 em diante). Para analisar a fala dessa localidade, vamos considerar alguns postulados sobre o modelo de comunidade de fala proposto por Guy (2000, p. 21):

\footnotetext{
${ }^{1}$ Martins (2013) é o trabalho de tese de doutorado defendido na Universidade Federal de Santa Catarina, no ano de 2013, sob a orientação da professora Izete Lehmkuhl Coelho.

${ }^{2} \mathrm{O}$ município de Fonte Boa, de acordo com dados do IBGE 2010, é dividido em zona urbana (sede da cidade) e zona rural (comunidades ribeirinhas). Martins (2013) coletou dados de fala na zona considerada urbana. No entanto, é importante ressaltar que neste artigo estamos considerando Fonte Boa como uma localidade menos urbana por apresentar alguns traços de ruralidade ao compará-la a grandes centros urbanos, como, por exemplo, Manaus, capital do Amazonas (cf. seção 2).

${ }^{3}$ Vale ressaltar que, devido a enviesamentos, a variável 'classe gramatical foi retirada da rodada por se sobrepor à variável 'posição em relação ao núcleo/núcleo'.
} 
Primeiro, o modelo de comunidade de fala postula que os falantes não variam aleatoriamente uns dos outros, ou ao menos não variam aleatoriamente em todos os tipos de variáveis. A participação em uma comunidade e o processo de acomodação garantem que muitos traços linguísticos serão mantidos em comum nessa comunidade. Segundo, o modelo de comunidade fornece uma base social e externa para investigar quem compartilha que traço com quem.

Considerando essas conjecturas de Guy (2000), acreditamos que os falantes de Fonte Boa "não variam aleatoriamente uns dos outros ou ao menos não variam aleatoriamente em todos os tipos de variáveis”. Assim, entender os graus de semelhança e de diferenças linguísticas que envolvem o uso de traços linguísticos pelos participantes dessa localidade, quando comparados com traços de falantes de outras localidades, é um dos objetivos deste trabalho. Uma discussão importante com respeito a generalidades e especificidades entre as comunidades de fala, no âmbito da sociolinguística brasileira, pode ser observada no texto de Görski e Coelho (2012) sobre aspectos de comportamento sociolinguístico entre as três capitais da Região Sul.

Nosso artigo está assim organizado: na primeira parte, apontamos alguns trabalhos realizados no Brasil a respeito da "concordância nominal de número", mostrando, dessa forma, que se trata de um fenômeno variável no PB. Em seguida, apresentamos, com mais detalhes, a caracterização da amostra. Por fim, retomamos os resultados encontrados por Martins (2013) na cidade de Fonte Boa $(\mathrm{AM})$ a fim de mostrar qual variante é mais utilizada na localidade, assim como quais grupos de fatores atuam ou não sobre o fenômeno em questão. Fechamos a discussão com algumas reflexões sobre particularidades e generalizações encontradas nessa localidade, considerando os resultados de outros estudos a respeito do mesmo fenômeno investigado em diferentes regiões brasileiras.

\section{SOBRE A CONCORDÂNCIA NOMINAL DE NÚMERO NO BRASIL}

Dentre os estudos dedicados ao tema da concordância nominal de número, podemos citar: i) em 1976, a pesquisa de Scherre e Braga, na qual foi analisada a fala de sete moradores do Rio de Janeiro, controlando 'classe social' e origem geográfica'; ii) em 1977, o trabalho de Braga, em que foi investigada a fala de sete moradores do triângulo mineiro em sua dissertação de mestrado; iii) em 1979, o estudo de Ponte, cuja análise focalizou a fala de vinte moradores de Porto Alegre (RS), todos analfabetos, em sua dissertação de mestrado; iv) em 1980, o trabalho de Nina, tendo sido investigada a fala de vinte moradores de Bragantina (PA) em sua dissertação de mestrado; v) em 1981, por fim, a pesquisa de Guy, que analisou os dados de moradores do Rio de Janeiro, coletados para o Projeto Competências Básicas, sob a coordenação da professora Miriam Lemle. Os referidos trabalhos serviram como ponto de partida para as pesquisas sociolinguísticas sobre fenômenos morfossintáticos realizados no Brasil.

Além dessas pesquisas, podemos apontar duas investigações de Scherre: uma de 1978, na qual a autora investigou a fala de dez moradores da zona urbana do Rio de Janeiro, em uma dissertação de mestrado; e outra de 1988, na qual estudou, em sua tese de doutorado, a fala de moradores do Rio de Janeiro, com o objetivo de reanalisar esse fenômeno comparando com os resultados de outras pesquisas.

Os trabalhos de Scherre (1978 e 1988), por sua vez, acabaram se tornando a base para muitos outros trabalhos realizados no Brasil sobre a "concordância nominal de número". Isso pode ser afirmado tendo em vista que as investigações que se seguiram replicaram as mesmas variáveis independentes controladas pela referida pesquisadora, especialmente as linguísticas. Dentre esses novos estudos, destacam-se: Dias (1993), sobre o falar dos moradores de Brasília; Fernandes (1996), referente aos dados de fala da Região Sul do Brasil; R. Carvalho (1997), com foco na fala de informantes da cidade de Rio Branco (AC); H. Carvalho (1997), relativo à fala de moradores de João Pessoa (PB); Lopes (2001), no que tange a dados de fala de informantes de Salvador (BA); Campos e Rodrigues (2002), tratando de dados de fala provenientes do Projeto Norma Urbana Culta (doravante NURC); Baxter (2009), concernente à fala de duas comunidades rurais de afrodescendentes, uma no Brasil (Helvécia - BA) e outra na África (Tongas, roça Monte Café, na República de São Tomé e Príncipe); Veis Ribeiro, Ribeiro e Loregian-Penkal (2009), no que se refere à fala dos nativos de Irati (PR); Santos (2010), acerca da fala dos informantes do município Pedro Leopoldo (MG); Martins (2010), quanto à fala de moradores do município Benjamin Constant (AM); Silva (2011), abarcando dados de fala da cidade de Vitória (ES); Brandão (2011), no tocante 
à fala de informantes de duas variedades urbana do português, uma do Brasil (Nova Iguaçu-RJ) e outra em São Tomé e Príncipe; Castro e Pereira (2012), sobre a fala de informantes da cidade de Cuiabá (MT); Martins (2013), no que diz respeito a dados de fala de informantes da microrregião do Alto Solimões (AM), dentre outros.

Os resultados dos trabalhos mencionados mostram que a "concordância nominal de número" trata-se de um fenômeno variável no $\mathrm{PB}$, assim como há grupos de fatores linguísticos e extralinguísticos comuns regendo a sistematicidade dessa variação. Dentre as variáveis linguísticas controladas nesses trabalhos, as que têm se mostrado relevantes são: i) 'relação de anteposição e posposição de elementos não nucleares em relação ao núcleo'; ii) 'marcas precedentes' e iii) 'saliência fônica't. Em relação aos grupos de fatores extralinguísticos, os que se mostraram relevantes, de maneira geral, nas pesquisas já realizadas no Brasil, foram i) 'escolaridade’ e ii) 'sexo's. A seguir, a Figura 1, sintetiza algumas cidades onde já foram realizadas pesquisas sobre o fenômeno aqui em discussão, até o ano de 2013, assim como ilustra os resultados gerais, em percentuais, das pesquisas aqui destacadas:

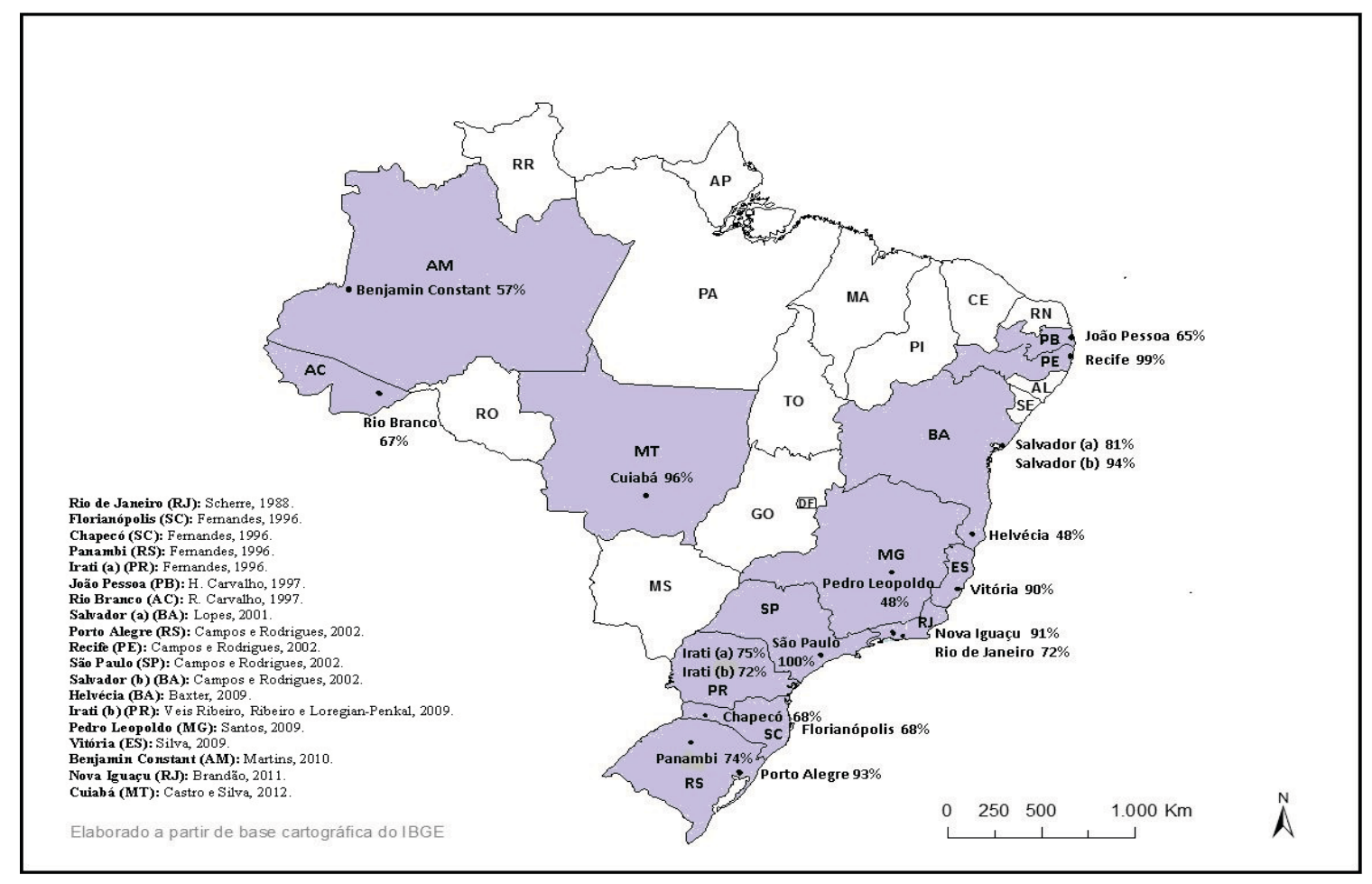

Figura 1: Frequência de uso das variantes da concordância nominal de número em alguns trabalhos realizados no Brasil

Fonte: Adaptado de Martins (2013)

Para os propósitos desta pesquisa apresentamos detalhadamente os resultados de Scherre (1988) sobre a fala da Região Sudeste, devido à sua contribuição significativa em relação ao tema, assim como o de Fernandes (1996), por se tratar de uma análise que se apoiou no envelope de variação utilizado por Scherre (1988), ampliando a discussão para a Região Sul do Brasil.

O corpus da pesquisa de Scherre (1988) foi constituído por 64 informantes residentes no Rio de Janeiro (RJ). As entrevistas totalizaram 64 horas de fala gravada, realizadas em dois períodos: i) de 1982 a 1984, com informantes entre 15 a 71 anos de idade, totalizando-se 48 entrevistas; ii) de 1983 a 1985, com informantes entre 7 a 14 anos, num total de 16 entrevistas.

\footnotetext{
${ }^{4}$ Desde Scherre (1988), a variável 'saliência fônica' tem sido considerada a partir da correlação entre as variáveis 'processos morfofonológicos de formação de plural' e 'tonicidade dos itens lexicais'.

${ }^{5}$ Ressalta-se que as pesquisas mencionadas não controlaram sempre os mesmos grupos de fatores extralinguísticos e linguísticos. Neste artigo, faz-se apenas uma generalização a partir da comparação dos resultados gerais dos referidos estudos.
} 
A primeira amostra foi estratificada de acordo com três variáveis sociais clássicas: a) 'anos de escolarização' ( 1 a 4 anos; 5 a 8 anos e 9 a $11 \operatorname{anos}^{6}$ ); b) 'sexo': feminino e masculino; c) 'faixa etária': 15 a 25 anos; 26 a 49 anos e 50 anos em diante. A segunda amostra - que completa a primeira - foi estratificada de acordo também com três variáveis sociais clássicas: a) 'anos de escolarização': 1 a 4 anos e 5 a 8 anos; b) 'sexo': feminino e masculino; c) 'faixa etária': 7 a 14 anos.

Scherre (1988) fez dois tipos de análises após a coleta dos SNs transcritos (7.193) das entrevistas, no que tange aos grupos de fatores linguísticos controlados nessa pesquisa: atomística, que consiste na observação da relação entre os elementos do SN; e não atomística, que consiste na observação da relação entre os SNs no plano oracional. Para a descrição e a análise dos dados, a autora utilizou o programa computacional denominado VARBRUL.

$\mathrm{Na}$ análise atomística, foram obtidos 13.229 dados após a devida categorização. Das dez variáveis linguísticas independentes controladas individualmente ou cruzadas, as selecionadas pelo programa estatístico utilizado pela pesquisadora, por ordem de seleção, foram oito: 'marcas precedentes em função da posição', 'saliência fônica' (a partir da correlação entre processos morfofonológicos de formação de plural e tonicidade dos itens lexicais), 'relação dos elementos não nucleares em função do núcleo e posição dos elementos nucleares no SN', 'formalidade dos substantivos e adjetivos', 'grau dos substantivos e adjetivos', 'animacidade dos substantivos', 'contexto fonético-fonológico seguinte' e 'função resumitiva'. As variáveis que não se mostraram significativas foram duas: 'número de sílabas dos itens lexicais singulares' e 'processos morfofonológicos de formação de plural'.

Na análise não atomística, por sua vez, foram obtidos 948 SNs de mais de dois elementos (SCHERRE, 1988), dos quais 72\% aparecem na amostra com marcação de concordância e 28\% sem marcação de concordância. Das nove variáveis linguísticas controladas, apenas sete atuaram nesse fenômeno como favorecedoras de marcação de concordância. Foram elas: 'pluralidade do contexto', 'configuração sintagmática do $S N$ ', 'saliência fônica' (dimensão processos), 'grau/ formalidade do SN', 'pluralidade do $S N$ ', 'função textual do SN' e 'localização do SN em relação ao verbo ou à oração'. Não se mostraram significativas duas variáveis: 'status informacional do $S N$ ' e 'animacidade do SN'.

$\mathrm{Na}$ análise das variáveis extralinguísticas independentes, por sua vez, controladas de forma isolada, primeiramente, o programa mostrou que as seguintes variáveis exercem um papel importante no fenômeno em foco: 'sexo' ' 'grau de escolaridade'. Uma análise desse fenômeno observando outros fatores sociais como 'origem social' de cada informante relacionado ao seu grau de concordância (alto ou baixo) revelou duas tendências interessantes, uma vez que os resultados mostraram uma maior influência da 'faixa etária'. Assim, Scherre (1988, p. 441; 515) evidencia:

a) "variação sociolinguística estável, com gradação etária, para os falantes de ambiente não humilde e de concordância alta" (15-25 anos: 0,44; 26-49 anos: 0,64; 50-71 anos: 0,41);

b) "processo de mudança linguística, caminhando em direção a um sistema sem concordância, para os falantes de ambiente humilde e concordância baixa" (15- 25 anos: 0,38; 26-49 anos: 0,59; 0,53).

Ainda, as seguintes variáveis sociais, não convencionais, mostraram também exercer influência sobre o fenômeno investigado: 'mercado de trabalho', 'mídia" e 'sensibilidade linguística'.

Um dos trabalhos a respeito da concordância nominal de número no PB que se apoiou na metodologia variacionista utilizada por Scherre (1988) foi o de Fernandes (1996) sobre a fala da Região Sul do Brasil. A autora investigou a variação na concordância de número na fala de 47 informantes da Região Sul, de três níveis de escolaridade (primário, ginásio e colegial) e duas faixas etárias (25 a 49 anos; mais de 50 anos), extraídos do banco de dados do projeto Variação Linguística da Região Sul (VARSUL) ${ }^{7}$. Para este

\footnotetext{
${ }^{6}$ Também foram entrevistados informantes com nível superior, completo ou não, mas a pesquisadora não os considerou na pesquisa por já estarem sendo estudados na época em um projeto específico: projeto NURC.

${ }^{7}$ A amostra de fala do Varsul investigada por Fernandes (1996) foi constituída de 30 minutos de fala de cada um dos informantes estratificados da seguinte maneira: 12 informantes de Florianópolis/SC (etnia açoriana, 6 homens e 6 mulheres), 12 informantes de Chapecó/SC (etnia italiana, 6 homens e 6 mulheres), 12 informantes de Panambi/RS, totalizando 24 horas de gravação e 5.424 dados.
} 
trabalho, consideramos apenas os resultados dos 12 informantes de Florianópolis ${ }^{8}$, os quais apresentaram 68\% de marcação de concordância de número. As variáveis linguísticas e extralinguísticas selecionadas pelo programa estatístico Varbrul nessa localidade foram: 'distribuição dos elementos do SN em função de sua posição e de sua relação com o núcleo', 'níveis de escolarização', 'marcas precedentes', 'saliência fônica', 'idade', 'etnia', 'grau dos substantivos e adjetivos', 'sexo', 'contexto seguinte' e 'tonicidade dos itens lexicais'. Os resultados mostraram que a marcação da concordância de número estava sujeita às mesmas restrições linguísticas e às mesmas forças sociais encontradas no trabalho de Scherre (1988).

Os trabalhos de Scherre (1988) e Fernandes (1998) trouxeram resultados importantes que foram levados em consideração na pesquisa de Martins (2013), a qual tratamos neste artigo.

Na seção que segue, apresentaremos a caracterização da amostra de Martins (2013), com destaque para a localidade de Fonte Boa. Ressalta-se que a referida pesquisa replicou variáveis linguísticas e extralinguísticas controladas por Scherre (1988) e acrescentou outras duas variáveis sociais que se mostraram importantes em outros fenômenos linguísticos estudados no Brasil: 'mobilidade' e ‘localismo’(BATTISTI et al. 2007; MONGUILHOTT, 2009).

\section{CARACTERIZAÇÃO DA AMOSTRA}

A amostra ora investigada pertence a um banco particular de dados de fala, coletado por Martins (2013) para sua tese de doutorado. A autora investigou cinco das nove cidades pertencentes à microrregião do Alto Solimões, que fica localizada ao oeste do Estado do Amazonas: São Paulo de Olivença, Santo Antônio do Içá, Tonantins, Jutaí e Fonte Boa. Para a realização da pesquisa, foi necessário coletar as entrevistas in loco, coleta que foi feita durante o mês de agosto de 2010. Quanto ao deslocamento até as cidades investigadas, foram utilizados meios de transporte aéreo e fluvial. Para a realização das entrevistas, foi utilizado o gravador digital Panasonic RR-US571.

A seguir, a Figura 2, ilustra um mapa localizando as cidades pertencentes à microrregião estudada (IBGE, 2009):

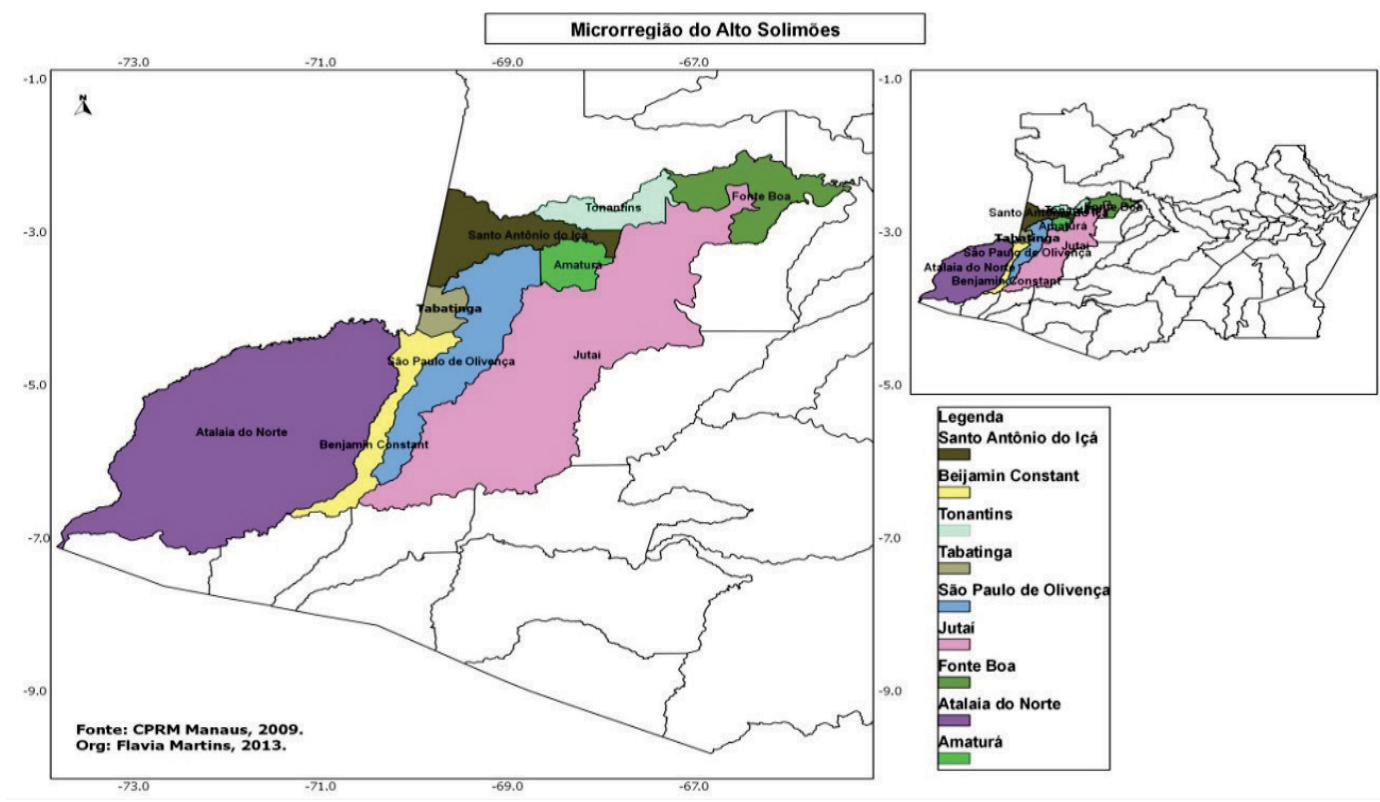

Figura 2: Mapa da microrregião do Alto Solimões (AM) Fonte: Adaptado de Martins (2013)

\footnotetext{
${ }^{8}$ Optamos por trazer os resultados de Florianópolis por ser uma comunidade colonizada por portugueses, e, nesse sentido, poderia mostrar resultados muito parecidos com os encontrados em Fonte Boa.
} 
No que tange ao perfil dos sujeitos que compuseram a amostra, foram entrevistados doze informantes em quase todos os cinco municípios selecionados pertencentes à microrregião do Alto Solimões. Pelo fato de algumas células não terem sido preenchidas no município de Jutaí e Fonte Boa, ficaram, no total, 57 informantes, estratificados de acordo com 'faixa etária' (18 a 35 anos, 36 a 55 anos, 56 em diante), 'sexo' e 'escolaridade' (quatro a oito anos de escolarização e nove a onze anos de escolarização).

Destaca-se, em particular, a dificuldade encontrada em Fonte Boa em relação à coleta de dados. No referido município, a naturalidade dos pais dos informantes e a baixa escolaridade dos moradores da cidade foram os empecilhos encontrados para conseguir fechar as células sociais traçadas para a pesquisa. Por exemplo, não foi possível encontrar moradores mais velhos cujos pais fossem também de lá (boa parte eram filhos de nordestinos). Ainda, não foi possível encontrar dois homens mais velhos que fossem mais escolarizados. No município de Fonte Boa, portanto, as células não foram todas preenchidas, ficando assim organizadas:

\begin{tabular}{l|c|c|c|c|c|c} 
& \multicolumn{2}{|c|}{18 a 35 anos } & \multicolumn{2}{c|}{36 a 55 anos } & \multicolumn{2}{c}{56 em diante } \\
\hline & Homem & Mulher & Homem & Mulher & Homem & Mulher \\
\hline 4 a 8 anos de escolarização & 1 & 1 & 1 & 1 & 1 & 1 \\
\hline 9 a 11 anos e escolarização & 1 & 1 & --- & 1 & --- & 1
\end{tabular}

Quadro 1: Estratificação social dos informantes de Fonte Boa

Fonte: As autoras.

É importante ressaltar que consideramos importante apresentar com mais detalhes os resultados da cidade de Fonte Boa neste artigo, tendo em vista que, dos cinco municípios investigados por Martins (2013), a referida cidade foi uma das que não favoreceu a aplicação da regra ${ }^{9}$, no caso a variante "presença de marcas formais/informais de plural”, como veremos na seção 3.

A seguir, será apresentado um breve perfil sócio-histórico da cidade de Fonte Boa para trazer elucidações acerca da realidade de região aqui investigada.

\subsection{PERFIL SÓCIO-HISTÓRICO}

O município de Fonte Boa, de acordo com o censo 2010, apresenta uma população de 22.817 habitantes, dividida em zona urbana (sede da cidade): 15.115 e zona rural (comunidades ribeirinhas): 7.702 . Sua área territorial corresponde a 12.110,93 km² e apresenta uma densidade demográfica de $1,88 \mathrm{hab} / \mathrm{km}^{2}$. Está situado à margem direita do rio Solimões, distante de Manaus (capital do Estado) em linha reta $680 \mathrm{~km}$ e por via fluvial $1.033 \mathrm{Km}$. O principal meio de transporte é o fluvial. Há aeroporto, mas no momento está em reforma. Recebia voos somente duas vezes por semana, na quarta-feira e no domingo. O município comemora seu aniversário na semana de 29 a 31 de março. Na Figura 3, a seguir, ilustramos a localização da cidade em foco neste artigo:

${ }^{9}$ De acordo com o resultado geral da pesquisa de Martins (2013): a partir da análise que abarca todos os municípios. 


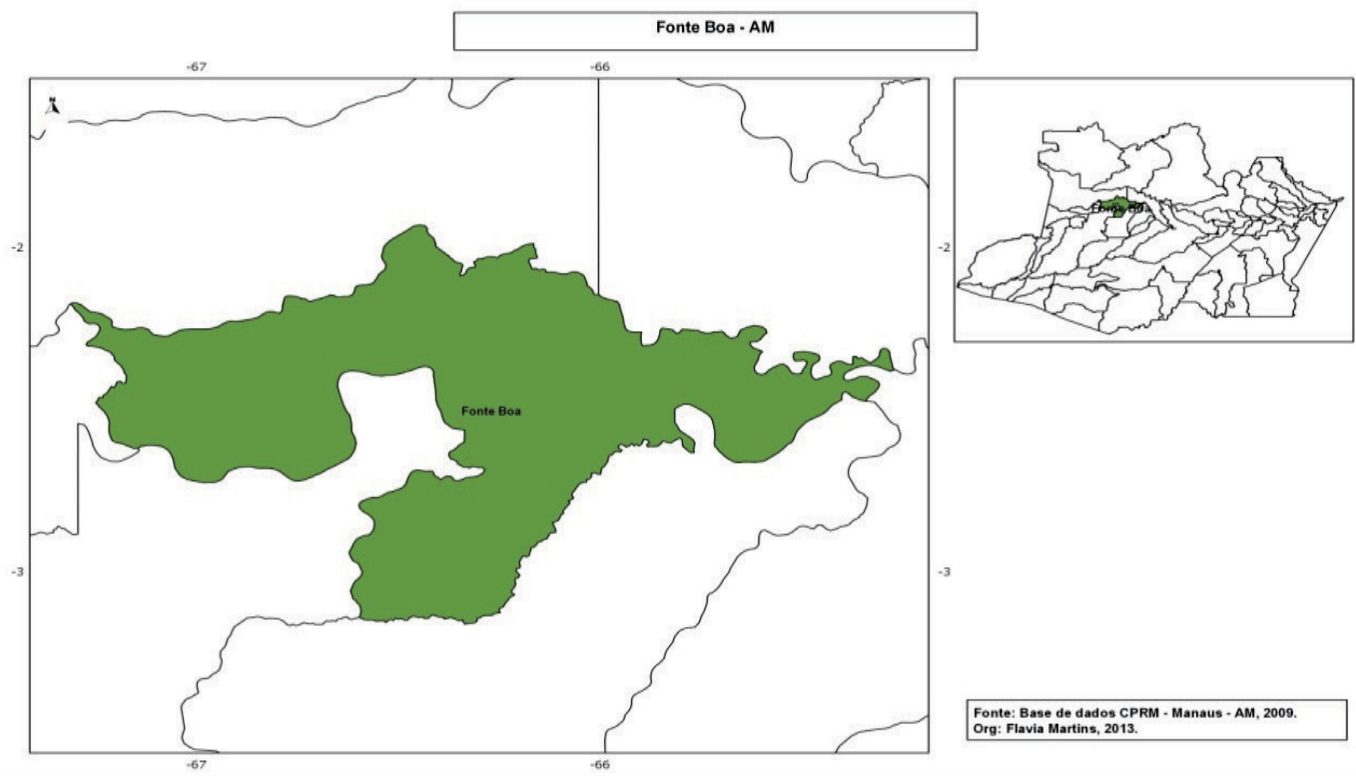

Figura 3: Mapa de Fonte Boa

Fonte: Adaptado de Martins (2013)

Segundo Migueis (2011), nesse município, viviam os indígenas da etnia Cambeba ${ }^{10}$ que povoavam o Alto Solimões. De acordo com Lisboa (1998, p. 158), "ao contrário do que se pensa, eram índios trabalhadores, místicos, politicamente bem organizados. De estatura alta e já ao primeiro contato com os missionários ${ }^{11}$ usavam roupas tecidas com algodão (planta abundante na região, na época)". Ainda segundo Lisboa (1998), esses índios, juntamente com o padre Samuel Fritz - missionário da Companhia de Jesus responsável pela ocupação da Amazônia pela Espanha -, fundaram a Missão de Nossa Senhora das Neves, que deu origem à atual cidade de Fonte Boa. A partir do contato com o branco, retrata Lisboa (1998, p. 158), esses índios não poderiam sobreviver a um violento massacre cultural e biológico (como epidemias etc).

Segundo o mesmo autor, entre os anos de 1751 a 1759, Fonte Boa passa a ser uma missão religiosa administrada pelos carmelitas que trabalhavam para o governo português, depois de acirradas disputas entre o governo espanhol e português devido ao novo Tratado de Tordesilhas. Os índios mostravam resistência ao governo português. Em 1759, a partir da rigorosa política de Marquês de Pombal, foi elevada à categoria de lugar. Em 1858, a cidade de Fonte Boa passa a ser reconhecida como freguesia, termo importante, tendo em vista que passa a ser considerada como colegiado, eleitora da atual cidade de Tefé.

Em 1891, no período áureo da borracha, segundo Lisboa (1998), é criado o município de Fonte Boa pelo decreto no 92, pois "as oligarquias locais, ou seja, o poder dos coronéis precisava ser forte e, com autonomia dos municípios, as administrações municipais aliadas ao poder dos governadores tornavam-se poderosas e prepotentes" (LISBOA, 1998, p. 49). Ressalta-se que esse período foi caracterizado pela presença de muitos nordestinos no Amazonas, inclusive em Fonte Boa, que vinham em busca do tão desejado látex. Eles implantaram no município o sistema de servidão, tirando proveito da acomodação indígena. Com essa miscigenação, deu-se origem "a outro tipo humano chamado caboclo" (LISBOA, 1998, p. 159).

Em 1938, segundo Migueis (2011), a sede do município é elevada à categoria de cidade pelo Decreto-Lei Estadual nº 68 . Esse período também é marcado pela segunda leva de nordestinos para a Amazônia em busca da borracha (período da Segunda Guerra Mundial, 1939-1945), intensificando a miscigenação do povo de Fonte Boa.

\footnotetext{
${ }^{10}$ Também conhecidos como Omáguas, do tronco Tupi.

${ }^{11}$ Segundo Lisboa, as primeiras missões realizadas na Bacia Amazônica eram provenientes da Espanha: "dona de grande parte da Bacia Amazônica, a Espanha confiara o trabalho de ocupação aos missionários da Companhia de Jesus, através de Pe. Samuel Fritz que, em nome do mesmo rei, descera e subira o Solimões inúmeras vezes, fundando missões, aldeando índios [...]" (p. 26). Em meados do século XVII é que a referida região passa a englobar missionários "tanto da parte espanhola como da portuguesa" (LISBOA, p. 37).
} 
Lisboa (1998, p. 161) conta que, nesse período, também "nota[va]-se a presença de estrangeiros, principalmente de Israel ${ }^{12}$, estes numerosos, fixaram residência aqui, praticando o comércio e outras atividades". Conta ainda que a presença dos negros foi

[...] menos inexpressiva. Mas deu também sua contribuição. Sua presença nessa região é incerta, uma vez que a região amazônica cedo dispensou o trabalho escravo, onde pouco se praticava a agricultura, exceto algumas regiões. É cabível deduzir que tenham vindo para cá na guerra da cabanagem, onde grupos de caboclos, índios e outras raças invadiram o Amazonas na intenção de protestar contra a Coroa Portuguesa, em prol de um governo que atendesse as necessidades regionais (LISBOA, 1998, p. 162).

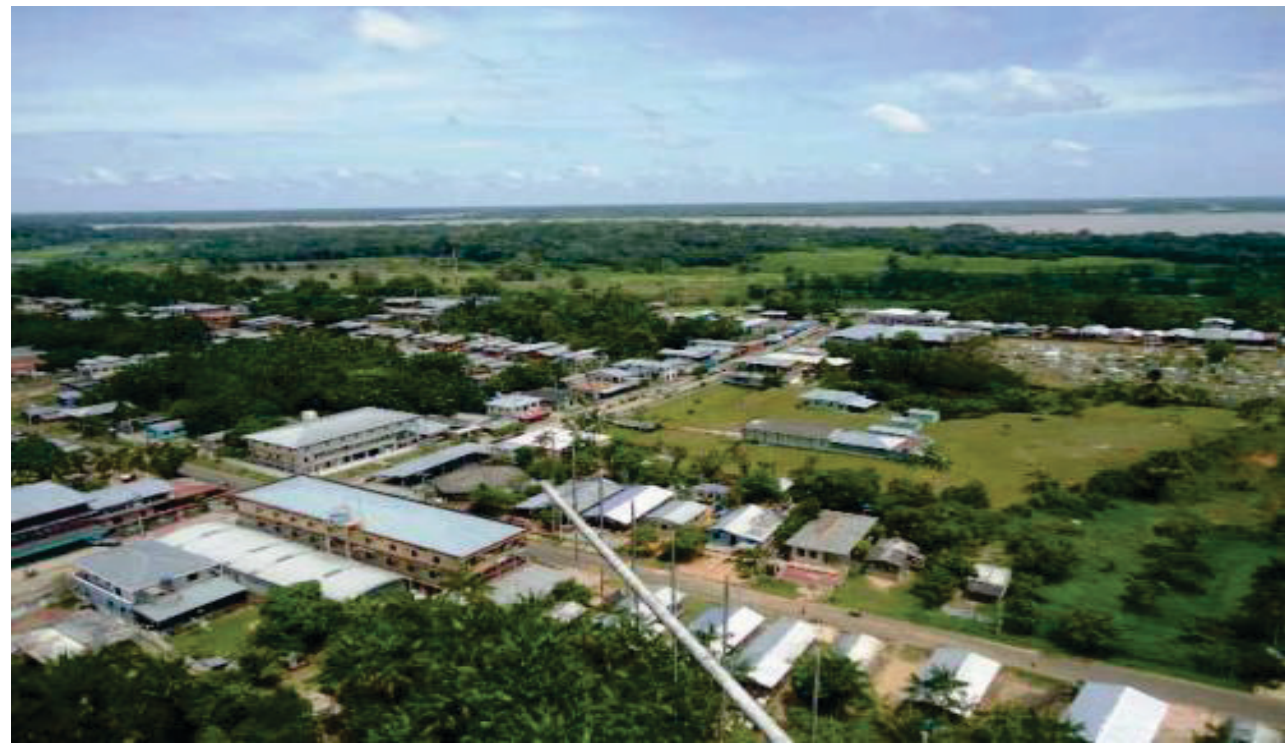

Figura 4: Vista aérea de Fonte Boa

Fonte: Alex Santos (Portal Fonte Boa)

Quanto à economia de Fonte Boa, é praticamente de subsistência e baseia-se no extrativismo vegetal e animal. Na produção vegetal, a cidade é um dos maiores produtores de madeira de lei. No pescado, conta com um grande número de lagos, e, com a ajuda do frigorífico, conseguem exportar para Manaus e outros Estados. A pecuária é extensiva, e existem inúmeros estabelecimentos comerciais.

Até o ano de 2012, no município de Fonte boa, na zona urbana, havia sete escolas (ainda há), sendo somente uma de ensino médio. Com isso, aqueles moradores que desejavam cursar alguma graduação, geralmente, deslocavam-se até outras cidades como Tefé, Coari ou Manaus. Essa situação até hoje acontece, embora em Fonte Boa já sejam ofertados alguns cursos de graduação ${ }^{13}$. Ressaltase que são poucos os habitantes de Fonte Boa que, quando saem do município para estudar, retornam, assim como acontece nas outras cidades investigadas por Martins $(2013)^{14}$.

\footnotetext{
${ }^{12}$ Presença, provavelmente, de pessoas que formariam o Estado de Israel (libaneses etc.).

${ }^{13}$ Vale destacar que a Universidade do Estado do Amazonas (UEA), de 2005 até atualmente, já ofertou 1 curso de graduação tecnológico: i) Produção Pesqueira (2008 a 2010) e 3 cursos de Licenciatura: i) Licenciatura em Educação Física (2014 a 2016); ii) Licenciatura em Matemática; e iii) Licenciatura em Língua Portuguesa (em curso desde 2016). Esses cursos aconteceram/acontecem de forma televisionada, mediado por tutoria (professor assistente). Os professores assistentes são formados na área da graduação ofertada. Esses professores ficam no município de Fonte Boa auxiliando os alunos durante as aulas que são transmitidas diretamente do Pólo da UEA, localizado em Manaus. Disponível em: http://cursos2.uea.edu.br/?viewMod=mun.

${ }^{14}$ Geralmente, os poucos que retornam são aqueles que fizeram a graduação nas seguintes áreas: Medicina, Enfermagem e Odontologia.
} 
No que trata ainda sobre a Educação, os dados do IBGE (2015) mostram que os alunos dos anos iniciais ${ }^{15}$ obtiveram nota média de 3.5 no IDEB, ao passo que os alunos dos anos finais obtiveram nota média de 2.9. Segundo o IBGE (2015),

[...] na comparação com cidades do mesmo estado, a nota dos alunos dos anos iniciais colocava esta cidade na posição 57 de 62. Considerando a nota dos alunos dos anos finais, a posição passava a 61 de 62 . A taxa de escolarização (para pessoas de 6 a 14 anos) foi de 84.8 em 2010. Isso posicionava o município na posição 49 de 62 dentre as cidades do estado e na posição 5527 de 5570 dentre as cidades do Brasil.

Quanto ao lazer, Fonte Boa conta com a festa da padroeira realizada na primeira semana de dezembro, Nossa Senhora de Guadalupe, momento em que a cidade recebe muitas pessoas de outras cidades próximas. No município, há ainda a Festa Junina na qual ocorrem diversas apresentações folclóricas. Nesse mesmo período, também acontece a grande "festa do boi" semelhante ao festival realizado em Parintins (AM). Em Fonte Boa, a disputa é entre os bois Corajoso, representado pela cor azul, e Tira-Prosa ${ }^{16}$, representado pela cor vermelha.

Outra festa que movimenta Fonte Boa acontece na última semana do mês de março quando se comemora seu aniversário, e há diversas atividades. A cidade também já contou com a Festa do Pirarucu que era realizada em novembro. Com base nisso, é possível notar que Fonte Boa caracteriza-se, em especial, pela presença indígena, pela presença de missões religiosas (tanto espanholas quanto portuguesas) e pela presença de nordestinos.

Na seção seguinte, apresentaremos os resultados encontrados por Martins (2013).

\section{DESCRIÇÃO DA VARIAÇÃO NA CONCORDÂNCIA NOMINAL DE NÚMERO EM FONTE BOA (AMAZONAS)}

Para este trabalho, foram analisados 1.356 dados a partir dos SNs coletados das entrevistas realizadas em Fonte Boa. Dessas ocorrências, o resultado geral da análise evidenciou 754 da variante "presença de marcas formais/informais de plural", correspondendo a 55\% dos dados, e 602 da variante "ausência de marcas formais/informais de plural", correspondendo 45\% dos dados. Dentre os municípios investigados (São Paulo de Olivença, Santo Antônio do Içá, Tonantins, Jutaí e Fonte Boa), pertencentes ao Alto Solimões, Fonte Boa e Tonantins apresentaram um desfavorecimento quanto ao uso da aplicação da regra ("presença de marcas formais/informais de plural"), conforme podemos observar na Tabela 1 a seguir.

Tabela 1: Frequência e probabilidade da variante "presença de marcas formais/informais de plural", segundo a variável diatopia

\begin{tabular}{c|c|c|c} 
Fatores & Aplicação/ Total & $\%$ & P.R. \\
\hline São Paulo de Olivença & $1191 / 1910$ & $62 \%$ & 0,57 \\
\hline Jutaí & $781 / 1211$ & $64 \%$ & 0,54 \\
\hline Santo Antônio do Içá & $895 / 1520$ & $58 \%$ & 0,51 \\
\hline Fonte Boa & $754 / 1356$ & $55 \%$ & 0,42 \\
\hline Tonantins & $643 / 1273$ & $50 \%$ & 0,41 \\
\hline
\end{tabular}

Significância: 0,048

Input: 0,723

Fonte: Martins (2013, p. 152).

\footnotetext{
${ }^{15}$ Disponível em: https://cidades.ibge.gov.br/brasil/am/fonte-boa/panorama

${ }^{16}$ A realização das entrevistas em FB coincidiu com a festa do BOI-BUMBÁ que acontecia nessa cidade.
} 
Particularmente sobre a investigação em Fonte Boa, localidade em investigação, vale ressaltar algumas decisões metodológicas que foram tomadas acerca das variáveis independentes, a partir da análise estatística realizada com a utilização do programa GoldVarb 2001. Foram investigadas as variáveis 'mobilidade’ e 'ocupação’ e excluídas da análise estatística com peso relativo por se sobreporem às variáveis 'escolaridade e 'idade', respectivamente. Ainda, foi necessário também excluir a variável 'localismo' da rodada estatística, pois houve knock-out, uma vez que $100 \%$ dos informantes se mostraram bem integrados à localidade a que pertencem ${ }^{17}$.

A seguir, ilustram-se alguns trechos das entrevistas realizadas em Fonte Boa, nos quais percebemos o grau alto de integração dos moradores à referida cidade:

\begin{tabular}{|c|c|}
\hline Perfil do Informante & Bem integrados \\
\hline $\begin{array}{l}\text { 1 a faixa etária, } 9 \text { a } 11 \text { anos de escolarização, mulher } \\
\qquad(001 \mathrm{BF}) .\end{array}$ & $\begin{array}{l}\text { E: tu gosta de Fonte Boa? } \\
\text { I: eu gosto... eu gosto de Fonte Boa... apesar de ser assim... um pouco... ser } \\
\text { calmo né? mas... é melhor... }\end{array}$ \\
\hline
\end{tabular}

E: mas aí prefere... trocaria Fonte Boa?... não?

1ª faixa etária, 4 a 8 anos de escolarização, homem (001 AM)

\section{I: ahn?}

E: trocaria Fonte Boa por outra cidade?

I: não porque eu sou filho daqui mesmo E: é... gosta daqui mesmo..

I: só se for pra outras cidades... só se for pra passear mesmo

\begin{tabular}{l|l} 
& I: só se for pra outras cidades... so se for pra passear mesmo \\
\hline
\end{tabular}

I: eu sempre gostei daqui... me orgulho de ser fonteboense...

E: uhnuhn

$1^{\text {a }}$ faixa etária, 9 a 11 anos de escolarização, homem (001 BM)

I: com certeza... não troco minha cidade por nada... por nenhuma outra E: uhnuhn

E: a senhora gosta daqui de Fonte Boa?

I: gosto

E: gosta... já morou em outra cidade... já visitou outra cidade alguma vez?

$2^{\text {a }}$ faixa etária, 9 a 11 anos de escolarização, mulher (002 BF)

$$
\text { I: já... mas... }
$$

E: trocaria... Fonte Boa por outra cidade? ((risos))

$$
\begin{gathered}
\text { I: não } \\
\text { E: não? }
\end{gathered}
$$

I: não trocaria Fonte Boa

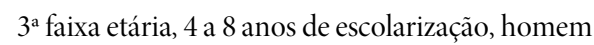
(003 AM)
I: nunca me afastei daqui... e não tenho vontade de abandonar Fonte Boa (também)... foi onde nasci... e... me criei ( )

Quadro 3: Trechos de algumas entrevistas realizadas em Fonte Boa (Amazonas) quanto ao Localismo Fonte: Adaptado de Martins (2013)

\footnotetext{
${ }^{17}$ Quanto ao 'localismo', essa variável foi assim definida: foram considerados bem integrados os informantes que gostam de morar na cidade, participam das atividades e não se manifestaram favoráveis à saída da cidade ou se manifestaram sair apenas por causa da educação dos filhos; foram considerados mais ou menos integrados os informantes que participam das atividades na cidade, mas gostariam de residir em outra cidade, ou se gostam de residir na cidade, mas não gostam das atividades que a cidade oferece; foram considerados pouco integrados aqueles informantes que não gostam de morar na cidade e nem participam das atividades na cidade.
} 
Com base nas entrevistas, detalhamos ainda no Quadro 4 o perfil dos informantes de acordo com as variáveis 'localismo', 'mobilidade' e 'ocupação':

\begin{tabular}{|c|c|c|c|c|c|c|c|}
\hline \multirow{2}{*}{ Informante } & \multirow[b]{2}{*}{ Profissão } & \multicolumn{3}{|c|}{ Localismo } & \multicolumn{3}{|c|}{ Mobilidade } \\
\hline & & Bem integrado & $\begin{array}{c}\text { Mais ou menos } \\
\text { integrado }\end{array}$ & Pouco integrado & Muita & Média & Pouca \\
\hline $001 \mathrm{AF}^{18}$ & Dona de casa & $\mathrm{X}$ & & & ------ & ---- & ---- \\
\hline $001 \mathrm{BF}$ & Manicure/ pedicure & $\mathrm{X}$ & & & & & $\mathrm{X}$ \\
\hline $001 \mathrm{AM}$ & Moto-táxi & $\mathrm{X}$ & & & $\mathrm{X}$ & & \\
\hline $001 \mathrm{BM}$ & $\begin{array}{l}\text { Funcionário público } \\
\text { (FUNASA) }\end{array}$ & $\mathrm{X}$ & & & $\mathrm{X}$ & & \\
\hline $002 \mathrm{AF}$ & Cozinheira (colégio) & $\mathrm{X}$ & & & $\mathrm{X}$ & & \\
\hline $002 \mathrm{BF}$ & Agente de saúde & $\mathrm{X}$ & & & $\mathrm{X}$ & & \\
\hline 002 AM & Comerciante & $\mathrm{X}$ & & & $\mathrm{X}$ & & \\
\hline $002 \mathrm{BM}$ & --.---.-- & ------- & ------ & -------- & ----- & ----- & ---- \\
\hline $003 \mathrm{AF}$ & Aposentada & $\mathrm{X}$ & & & $\mathrm{X}$ & & \\
\hline $003 \mathrm{BF}$ & Professora aposentada & $\mathrm{X}$ & & & $\mathrm{X}$ & & \\
\hline 003 AM & Fazendeiro & $\mathrm{X}$ & & & & & $\mathrm{X}$ \\
\hline $003 \mathrm{BM}$ & ---------- & -------- & --------- & -------- & ----- & ---- & --- \\
\hline
\end{tabular}

Fonte: Adaptado de Martins (2013)

Fonte Boa se apresenta como uma localidade em que os moradores são bastante integrados, independentemente de profissão. Apesar de mostrarem alta mobilidade, afirmam que não trocariam Fonte Boa por outra cidade para morar.

Após a exclusão das variáveis mencionadas, os grupos de fatores que mostraram atuar sobre a aplicação da regra foram os seguintes, por ordem de seleção: 'posição em relação ao núcleo/núcleo', 'marcas precedentes', 'escolaridade', 'saliência fônica' (a partir da correlação das variáveis 'processos morfofonológicos de formação de plural e tonicidade dos itens lexicais'), 'sexo' e 'contexto fonéticofonológico subsequente'.

A Tabela 2 traz os resultados percentuais e de peso relativo dos grupos de fatores linguísticos mais significativos:

Tabela 2: Frequência e probabilidade da variante 'presença de marcas formais/informais de plural' no município de FB, segundo as variáveis independentes linguísticas atuantes

\footnotetext{
${ }^{18}$ Para 001, leia-se: $1^{\text {a }}$ faixa etária; Para 002: 2a faixa etária; Para 003: $3^{\text {a }}$ faixa etária; Para A: 4 a 8 anos de escolarização; Para B: 9 a 11 anos de escolarização; Para F: mulher e para M: homem.
} 


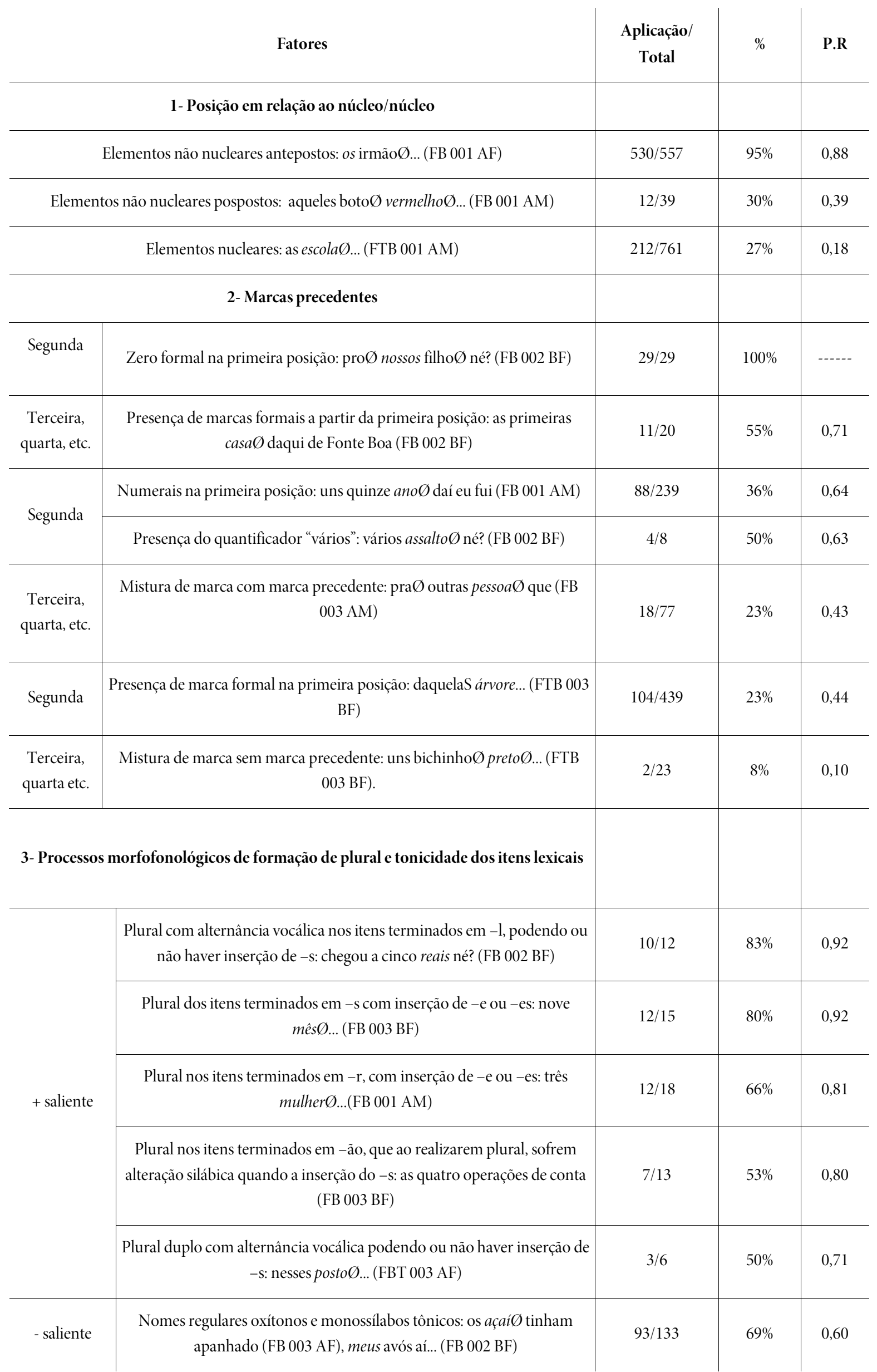




\begin{tabular}{|c|c|c|c|}
\hline Regular paroxítono: que os barcoØ passa por aqui (FB 003 AM) & $340 / 851$ & $39 \%$ & 0,45 \\
\hline Regulares proparoxítonos: os médicoØ entram no mato (003 AF) & $4 / 14$ & $28 \%$ & 0,31 \\
\hline \multicolumn{4}{|l|}{ 4- Contexto Fonético-Fonológico subsequente } \\
\hline Vogal: os filhoØ agora... o pai fala (FB $001 \mathrm{AF}$ ) & $131 / 201$ & $65 \%$ & 0,61 \\
\hline Pausa: as coisaØ... (FB 001 AF) & $111 / 355$ & $31 \%$ & 0,56 \\
\hline Consoante: meus paiØ... (FB 003 AM) & $512 / 801$ & $63 \%$ & 0,44 \\
\hline
\end{tabular}

Fonte: Martins (2013,p. 185)

Os resultados descritos na Tabela 2 mostram algumas tendências. Os índices da variável 'posição em relação ao núcleo/núcleo', selecionada em primeiro lugar, corroboraram os resultados de outras pesquisas sobre esse fenômeno no PB, segundo os quais os 'elementos não nucleares antepostos ao núcleo' favorecem a aplicação da regra $(0,88)$, enquanto os 'elementos não nucleares pospostos' e o 'núcleo' a desfavorecem $(0,39$ e 0,18 , respectivamente).

Em relação à variável 'marcas precedentes', selecionada em segundo lugar, foi observado que, dentre os SNs com três ou mais elementos somente o fator presença de marca formal a partir da primeira posição favorece a aplicação da regra (0,71), enquanto os fatores mistura de marca com marca precedente $(0,43)$ e mistura de marca sem marca precedente $(0,10)$ a desfavorecem. Esses resultados divergem em parte dos outros resultados encontrados no PB, pois se esperava, como foi encontrado em Scherre (1988), que o fator mistura de marcas com marca precedente também favorecesse a aplicação da regra.

No que tange à variável 'processos morfofonológicos de formação de plural e tonicidade dos itens lexicais' ('saliência fônica'), selecionada em quarto lugar, os resultados encontrados seguem, de maneira geral, resultados de outras análises sobre a fala do PB, uma vez que itens com formação de plural irregular favorecem a aplicação da regra, enquanto os de formação regular a desfavorecem. O que diverge dos resultados de outras pesquisas tem a ver com a hierarquia de atuação dos fatores tanto para os itens considerados mais salientes quanto para os menos salientes. Quanto aos mais salientes, o fator mais atuante sobre a aplicação da regra foi: os 'itens terminados em - $l$ '. No que se refere aos menos salientes, temos a seguinte hierarquia: 'regular oxítono e monossílabo tônico', 'regular paroxitono e regular proparoxitono'.

Já a variável 'contexto fonético-fonológico subsequente', selecionada em último lugar, também revelou resultados muito semelhantes aos de outras pesquisas realizadas no PB, pois foram observadas a 'vogal' e a 'pausa' favorecendo a aplicação da regra $(0,61$ e 0,56, respectivamente) e a 'consoante' desfavorecendo-a $(0,44)$.

Como observamos, variáveis independentes linguísticas se mostram importantes para entender o funcionamento da regra de "concordância nominal de número" no município de Fonte Boa.

No que se refere às variáveis independentes extralinguísticas selecionadas pelo programa estatístico ${ }^{19}$, foram encontrados os seguintes resultados:

\footnotetext{
${ }^{19}$ Vale ressaltar que foram levadas em consideração na rodada, como já mencionado, apenas três variáveis externas: 'idade', 'sexo' e 'escolaridade’. Dessas, apenas a variável 'idade’ não foi selecionada.
} 
Tabela 3: Frequência e probabilidade da variante "presença de marcas formais/informais de plural” no município de FB, segundo as variáveis independentes extralinguísticas atuantes

\begin{tabular}{|c|c|c|c|}
\hline Fatores & Aplicação/ Total & $\%$ & P.R. \\
\hline \multicolumn{4}{|c|}{ 1- Escolaridade } \\
\hline 9 a 11 anos & $428 / 681$ & $62 \%$ & 0,66 \\
\hline 4 a 8 anos & $326 / 676$ & $48 \%$ & 0,33 \\
\hline \multicolumn{4}{|l|}{ 2-Sexo } \\
\hline Homem & $238 / 412$ & $57 \%$ & 0,64 \\
\hline Mulher & $516 / 945$ & $54 \%$ & 0,43 \\
\hline
\end{tabular}

Em relação à escolaridade, grupo de fatores selecionado em terceiro lugar, foi atestado que informantes com maior tempo de exposição à escola tendem ao uso da variante de prestígio, "presença de marcas formais/informais de plural" $(0,66)$, enquanto os informantes expostos por menos tempo à escola tendem a não usá-la $(0,33)$. Esses índices de FB corroboram os resultados encontrados em outras regiões do Brasil.

No tocante à variável 'sexo', selecionada em quinto lugar, houve comportamento bem peculiar em Fonte Boa com índices altos de marcação de concordância na fala dos homens $(0,64)$, os quais favorecem o uso da variante de prestígio, enquanto as mulheres apresentam índices inferiores a 0,50 (0,43). Esses resultados divergem dos resultados encontrados para algumas pesquisas realizadas sobre o PB, mas convergem para os resultados encontrados na pesquisa de R. Carvalho (1997) realizada com informantes de Rio Branco (AC), na pesquisa de Baxter (2009) realizada com informantes de Helvécia (BA) e na pesquisa de Silva (2011) realizada com informantes da cidade de Vitória (ES). Para os dois primeiros autores, esse resultado é explicado em função do efeito da 'ocupação' dos informantes, pois os homens de sua pesquisa apresentavam um maior grau de integração social, sendo mais expostos, assim, a variantes de prestígio social do que as mulheres. A fim de atestarmos ou não essa explicação, foi feito um cruzamento entre a variável 'sexo'e a variável 'ocupação', como se pode verificar na Tabela 4:

Tabela 4: Frequência da variante "presença de marcas formais/informais de plural" em FB, segundo as variáveis sexo e ocuipação

\begin{tabular}{c|c|c|c} 
Sexo/Ocupação & Alta & Média & Baixa \\
\hline Homem & $89 \%$ & $47 \%$ & --- \\
\hline Mulher & $58 \%$ & --- & $55 \%$
\end{tabular}

Fonte: Martins (2013, p. 188)

Nesta localidade investigada, observou-se que os homens são mais sensíveis à variável 'ocupação'. Acreditamos que, conforme anteciparam Scherre (1988), R. Carvalho (1997) e Baxter (2009), os homens, por ocuparem cargos de maior integração social, tendam ao uso de variantes de prestígio. Nos resultados de Fonte Boa, dos quatro informantes homens entrevistados, três correspondiam ao que consideramos de cotação média (motoqueiro, comerciante e fazendeiro) e um de cotação alta (funcionário público da saúde). Das seis informantes mulheres entrevistadas, duas apenas eram de cotação alta (agente de saúde e professora aposentada) e as demais de cotação baixa (dona de casa, manicure, cozinheira e aposentada). 
Como se verifica na análise das variáveis independentes extralinguísticas, as variáveis sociais clássicas 'escolaridade' e 'sexo' se mostraram relevantes para entendermos a regra de 'concordância nominal de número' no município de FB. A essas variáveis estão atreladas as variáveis externas 'localismo', 'mobilidade' e 'ocupação'.

\section{5 À GUISA DE CONCLUSÃO: ALGUMAS REFLEXÕES SOBRE A VARIAÇÃO NA CONCORDÂNCIA NOMINAL DE NÚMERO EM FONTE BOA (AMAZONAS)}

Os resultados deste estudo da regra variável da concordância nominal de número no município de Fonte Boa revelam algumas tendências quando os comparamos com resultados gerais investigados por Scherre (1988) para a cidade do Rio de Janeiro, por Fernandes (1996) para Florianópolis e por Martins (2013) para as outras localidades investigadas do Alto Solimões (São Paulo de Olivença, Jutaí, Santo Antônio do Içá e Tonantins). Iniciamos essa comparação com os resultados gerais de marcação na concordância de número encontrados nessas localidades, como pode ser observado no gráfico a seguir.

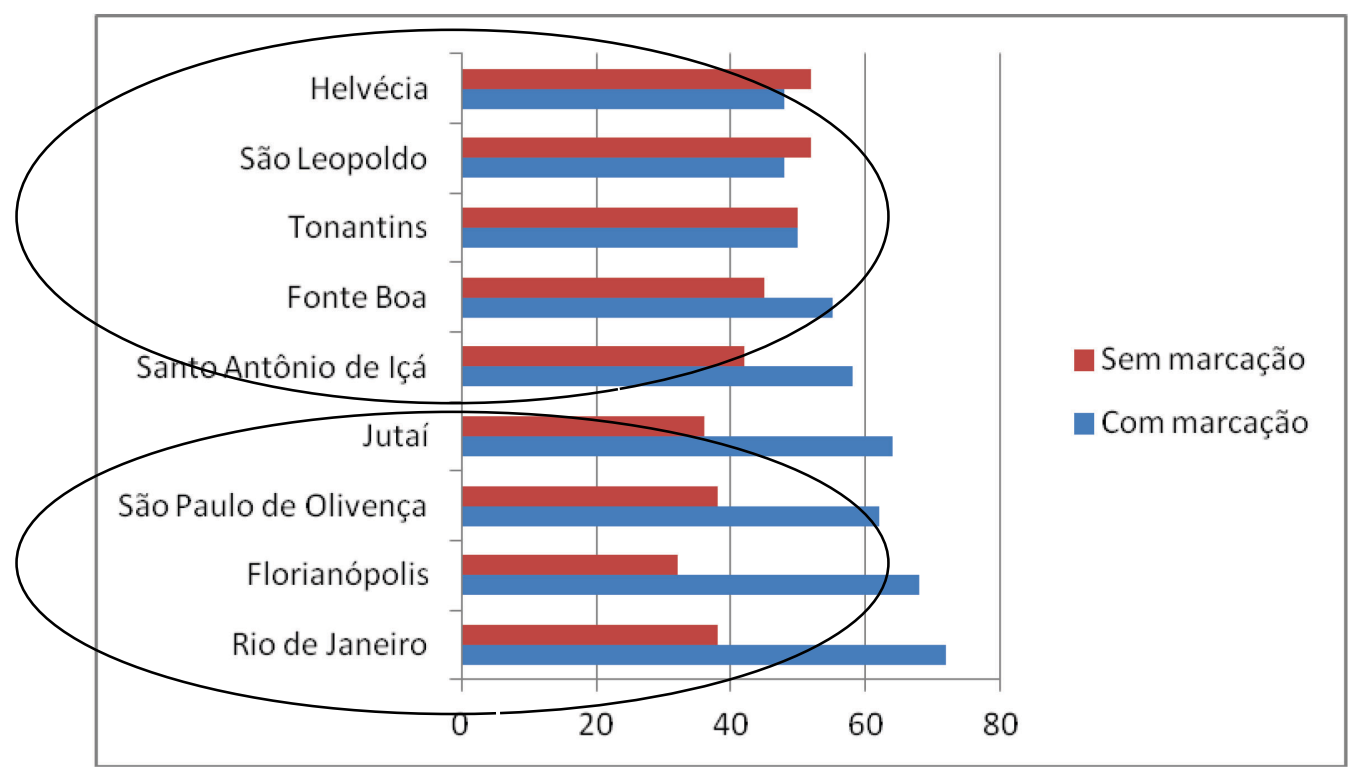

Gráfico 1: Percentual geral de concordância do SN em diferentes localidades brasileiras

Fonte: as autoras

Com base nos resultados percentuais gerais de marcação na concordância nominal em diferentes regiões brasileiras, podemos observar que Fonte Boa apresenta particularidades de comportamento com respeito à concordância de número. A localidade opõese a São Paulo de Olivença e Jutaíi ${ }^{20}$, localidades que muito se assemelham aos resultados do Rio de Janeiro (SCHERRE, 1988) e de Florianópolis (FERNANDES, 1996). Assemelha-se às cidades de Santo Antônio de Içá e Tonantins, que tendem mais para os resultados de São Leopoldo, em Minas Gerais (SANTOS, 2010), e de Helvécia, na Bahia (BAXTER, 2009). Essa distribuição revela que a variação na concordância nominal está diretamente relacionada à oposição entre mais urbano e menos urbano, ou entre urbano e rural. A oposição entre mais urbano e menos urbano parece revelar resultados interessantes, mostrando que os informantes de Fonte Boa, de zonas menos urbanas, reforçam os valores locais e linguísticos, tendendo ao uso da variante sem marcação de concordância; já os falantes de zonas mais urbanas acabam não reforçando os valores locais e linguísticos, tendendo a utilizar as formas mais escolarizadas e prestigiadas, como a marcação de concordância. Através da análise da variável 'localismo’ é

${ }^{20}$ Vale ressaltar que as localidades São Paulo de Olivença e Jutaí em termos demográficos e econômicos se assemelham às localidades de Fonte Boa, Santo Antônio do Içá e Tonantins. Entretanto, comportaram-se como zonas mais urbanas no que se refere ao resultado geral de concordância nominal de número. Talvez esse resultado reflita outras características sociais da comunidade, como mobilidade, localismo e ocupação. 
possível dizer que os informantes de Fonte Boa podem ser considerados bem-integrados à sua localidade, mantendo, portanto, os valores daquela localidade.

Apesar dessa diferença bastante acentuada entre os percentuais gerais de concordância, as variáveis independentes linguísticas relevam que a marcação da concordância nominal no município de Fonte Boa é regida, em grande medida, pelas mesmas restrições linguísticas das outras regiões do Brasil ${ }^{21}$, sejam essas regiões mais ou menos urbanas. A marcação da concordância nominal é favorecida pelos 'elementos não nucleares antepostos ao núcleo' (0,88), pelas 'marcas precedentes a partir da primeira posição' (0,71, 0,64 e 0,63), pelos 'processos morfofonológicos mais salientes' $(0,92,0,92,0,81,0,80$ e 0,71$)$ e pelo 'contexto fonológico subsequente', especialmente quando esse contexto for representado por vogal $(0,61)$ e pausa $(0,56)$.

De acordo com a análise das variáveis independentes extralinguísticas, os resultados de Fonte Boa apontam para alguns comportamentos particulares, que se distinguem do resultado geral, apresentado no Gráfico 1. A variável 'escolaridade’ apresenta a mesma tendência de outras regiões mais urbanas do Brasil, como Rio de Janeiro e Florianópolis, segundo a qual os informantes com maior tempo de exposição à escola tendem ao uso da variante de prestígio, com 0,66 de marcação de concordância, contra 0,33 na fala de informantes menos escolarizados. Entretanto, essa variável não se mostrou significativa para a maioria dos resultados relativos às outras localidades do Amazonas (cf. MARTINS, 2013). Nesse sentido, em Fonte Boa, o estabelecimento da regra de concordância parece ser mais sensível à variável 'escolaridade', o que indica uma maior preocupação com a variante de maior prestígio.

No que tange à variável 'sexo', os índices de Fonte Boa divergem de outras regiões urbanas do Brasil, assemelhando-se nesse caso à localidade de Helvécia. O que chama a atenção nos resultados dessa variável social é o alto índice de marcação de concordância na fala de informantes do sexo masculino, correlacionado com o fator ocupação alta como agente de mudança, com 89\% de marcação de concordância. Nos índices das mulheres, o fator ocupação alta se revela pouco atuante, com apenas 58\% de marcação. Essa diferença mostra um comportamento particularizado de uma localidade em que a mulher atua em 55\% dos casos em profissões consideradas de ocupação baixa (dona de casa, manicure, cozinheira e aposentada). Nesse sentido, seria possível dizer que a marca de prestígio é sensível ao sexo masculino.

O que os resultados nos autorizam a dizer acerca dos padrões sociolinguísticos comuns e divergentes entre a fala de Fonte Boa e a fala de outras regiões aqui investigadas, nos termos de Guy (2000)?

Com base nos resultados apresentados, podemos fazer alguma generalização entre Fonte Boa e outras regiões brasileiras mais e menos urbanas, indicando um certo paralelismo interdialetal dos padrões de variação na concordância nominal de número com base em graus de semelhança e de diferenças linguísticas que envolvem o uso de traços linguísticos pelos participantes dessa localidade. De modo geral, Fonte Boa revela um índice baixo de marcação de concordância (55\%), indicando valores semelhantes aos encontrados em zonas menos urbanas, em que os informantes reforçam os valores locais.

Ao observarmos os resultados das variáveis extralinguísticas, duas direções podem ser vislumbradas. De um lado, a marcação da concordância se revela sensível à variável 'escolaridade', uma marca compartilhada especialmente pelas comunidades mais urbanas aqui investigadas. De outro lado, a variável 'sexo' releva comportamento distinto daquele que se verifica nessas comunidades mais urbanas. A dicotomia rural versus urbano pode estar relacionada à variável 'sexo' nesse caso: homens e mulheres apresentam comportamento diferenciado nas zonas urbanas e nas zonas rurais. Em Fonte Boa os papeis de mulheres e homens ainda são conservadores, sendo a mulher menos sensível à variável 'mercado de trabalho'. Os homens daquela amostra apresentam um maior grau de integração social, por atuarem especialmente em ocupações mais prestigiadas na sociedade, sendo mais expostos, assim, às variedades de maior prestígio social do que as mulheres.

\footnotetext{
${ }^{21}$ No trabalho de Martins (2013), a autora observa que nas cinco localidades do Alto Solimões investigadas as mesmas variáveis linguísticas foram selecionadas, mas nem sempre na mesma ordem de seleção e nem sempre na mesma hierarquia dos fatores atuantes. Para os propósitos deste trabalho, o que importa é que os mesmos grupos linguísticos tenham sido selecionados.
} 
Vale lembrar que esse debate entre a fala das mulheres e o prestígio ainda é muito incipiente na sociolinguística brasileira. Um estudo importante a esse respeito é o de Freitag (2015, p.67), por trazer questões polêmicas concernentes ao "[...] valor simbólico da linguagem dominante e das variedades de prestígio em termos de seu suposto valor econômico no mercado de trabalho [...] [e em termos da] atenção às ideologias da masculinidade e da feminilidade”.

\section{REFERÊNCIAS}

BATTISTI, E et al. Palatalização das oclusivas alveolares e a rede social dos informantes. Revista Virtual de Estudos da LinguagemReVel. v. 5, n. 9, ago. 2007.

BAXTER, A. A concordância de número. In: LUCCHESI, BAXTER e RIBEIRO (orgs). O português afro-brasileiro. Salvador: EDUFBA, 2009. p. 269-293.

BRAGA, M. L. A concordância de número no sintagma nominal no triângulo mineiro. 1977. Dissertação (Mestrado em Língua Portuguesa) - Universidade Católica do Rio de Janeiro, Rio de Janeiro, 1977.

BRANDÃO, S. Fo. Concordância nominal em duas variedades do português: convergências e divergências. Revista Veredas. Atemática, 164-178, 1/2011.

CAMPOS, O. G. L. de S.; RODRIGUES, Â. C. S. Flexão nominal: indicação de pluralidade no sintagma nominal. In: ILARI, R (org.). Gramática do português falado. Volume II: níveis de análise linguística. 4. ed. Campinas (SP): editora da UNICAMP, 2002. p. 101102.

CARVALHO, H. Concordância nominal: uma análise variacionista. 1997. Dissertação (Mestrado em Letras), Universidade Federal de João Pessoa, João Pessoa, 1997.

CARVALHO, R. C. de. A concordância de número no sintagma nominal na fala urbana de Rio Branco. 1997. Dissertação (Mestrado em Linguística) - UNICAMP, Campinas, 1997.

CASTRO, F. M. B. de; PEREIRA, V. C. A concordância nominal na norma culta em Cuiabá. Revistas LetrasMil. v. 1, n. 3, p. 40-48, julho, 2012.

CRUZ, M. L. de C.. Atlas Linguístico do Amazonas - ALAM. 2004. Tese (Doutorado em Letras Vernáculas), UFRJ, Rio de Janeiro, 2 sem. 2004.

DIAS, M. C. A. C. A variação na concordância nominal: um contraste entre o urbano e o rural na fala brasiliense. $1993.178 \mathrm{f}$. Dissertação (Mestrado em Linguística) - Universidade de Brasília, Brasília, 1993.

FERNANDES, Marisa. Concordância nominal na região sul. 1996. Dissertação (Mestrado em Linguística), UFSC, Florianópolis, 1996.

FREITAG, R. M. K.; (Re)discutindo sexo/gênero na sociolinguística. In: FREITAG, R. M. K.; SEVERO, C. G. (org.). Mulheres, linguagem e poder - estudos de gênero na sociolinguística brasileira. São Paulo: Blucher, 2015. p. 17-74.

GÖRSKI, E. M. COELHO, I. L. Aspectos de comportamento sociolinguístico entre as três capitais da região sul: especificidades e generalizações. Revista do GELNE, Natal/RN, v.4, Número Especial, p.135-160, 2012.

Fórum linguistic., Florianópolis, v.16, n.4,p.4097-4117, out./dez.2019 
GUY, G. A identidade linguística da comunidade de fala: paralelismo interdialetal nos padrões de variação linguística. Organon, Porto Alegre, v.28/29, p. 17-32, 2000.

GUY, G. Linguistic variation Brazilian Portuguese: aspects of the phonology, sintax, and language history. 1981. Tese (Doutorado) - University of Pennsylvania, 1981.

LISBOA, H. Fonte Boa chão de heróis e fanáticos. Fonte Boa: Paróquia Nossa Senhora de Guadalupe, 1998.

LABOV, W Padrões sociolinguísticos. Trad. Marcos Bagno, Maria Marta Pereira Scherre, Caroline Rodrigues Cardoso. São Paulo: Parábola, 2008.

LOPES, N. Concordância nominal, contexto linguístico e sociedade. Salvador: UFBA, 2001.

MARTINS, F. S. Uma abordagem da concordância nominal de número na fala dos habitantes do município amazonense de Benjamin Constant. Revistas Working papers em Linguística, n. esp., p. 45-56, Florianópolis, 2010.

MARTINS, F. S. Variação na concordância nominal de número na fala dos moradores do Alto Solimões (Amazonas). 2013. Tese (Doutorado em Linguística) - Programa de Pós-Graduação em Linguística, Universidade Federal de Santa Catarina, Florianópolis, 2013.

MIGUEIS, R. Geografia do Amazonas. Manaus: Valer, 2011.

MONGUILHOTT, I. de O. e S. Estudo sincrônico e diacrônico da concordância verbal de terceira pessoa do plural no PB e no PE. 2009. Tese (Doutorado em Linguística- Programa de Pós-Graduação em Linguística, Universidade Federal de Santa Catarina, Florianópolis, 2009.

NINA, T. Concordância nominal/verbal do analfabeto na Micro-Região Bragantina. 1980. Dissertação (Mestrado) - Instituto de Letras e Artes, Pontifícia Universidade Católica do Rio Grande do Sul, Porto Alegre, 1980

PONTE, V. M. L. A concordância nominal de uma comunidade de Porto Alegre. 1979. 215 f. Dissertação (Mestrado em Linguística) - Pontifícia Universidade Católica do Rio Grande do Sul, Porto Alegre, 1979.

SANTOS, L. S. M. Sobre a ausência de concordância nominal no português falado em Pedro Leopoldo-MG: uma abordagem variacionista. 2010. Dissertação (Mestrado em Linguística) - Universidade Federal de Minhas Gerais, Belo Horizonte, 2010.

SCHERRE, M. M. P. Reanálise da concordância nominal em português. 1988. Tese (Doutorado em Linguística) - Faculdade de Letras, Universidade Federal do Rio de Janeiro, Rio de Janeiro, em dois volumes, 1988.

SCHERRE, M. M. P. Paralelismo linguístico. Revista de estudos da linguagem. v 7, n 2, p. 29-59, jul/dez, 1998 a.

SCHERRE, M. M. P. Aspectos da concordância de número no português do Brasil. Revista Internacional de Língua Portuguesa (RILP): Norma e variação do português. Associação das Universidades de Língua Portuguesa, dez. 1994.

SCHERRE, M. M. P. Concordância nominal e funcionalismo. Revista Alfa, n 41, 181-206, 1997. 
SCHERRE, M. M. P. Sobre a influência de três variáveis relacionadas na concordância nominal em português. In: SILVA, G. M. de O.; SCHERRE, M. M. P. Padrões sociolinguísticos: análise de fenômenos variáveis do português falado do Rio de Janeiro. 2 ed. Rio de Janeiro: Tempo Brasileiro, Departamento de Linguística e Filologia, UFRJ, 1998b. p. 85-117.

SCHERRE, M. M. P. Sobre a influência de variáveis sociais na concordância nominal. In: SILVA, G. M. de O.; SCHERRE, M. M . P. Padrões sociolinguísticos: análise de fenômenos variáveis do português falado do Rio de Janeiro. 2 ed. Rio de Janeiro: Tempo Brasileiro, Departamento de Linguística e Filologia, UFRJ, 1998c. p. 239-264.

SCHERRE, M. M. P. Sobre a concordância de número no português falado do Brasil. In: RUFINO, G. (org.). Dialettologia, geolingüística, sociolinguística (Atti del XXI Congresso Internazionale di Linguistica e Filologia Romanza). Centro di Studi Filologic e Linguistic Siciliani, Universitá di Palermo. Tübingen: Max Niemeyer Verlag, v.5, p.509-523, 1998.

SCHERRE, M. M. P. ; BRAGA, Maria Luiza. A concordância de número no SN na área urbana do Rio de Janeiro. In: ENCONTRO NACIONAL DE LINGUÍSTICA, 1., 1976. Anais... Rio de Janeiro, PUC, 1976. p. 464-477.

SILVA, J. B. da. A concordância nominal na fala capixaba. In: CONGRESSO NACIONAL DE ESTUDOS LINGUÍSTICOS, 1. Vitória- ES, 18 a 21 de outubro de 2011. Anais... Vitória, UFES, 2011, p. 1-4.

VEIS RIBEIRO, V.; LOREGIAN-PENKAL, L. O fator faixa etária e a concordância nominal na linguagem falada na cidade de Irati, PR. Revista Analecta, v.10, n.1, p.69-83, 2009.

WEINREICH, U.; LABOV, W.; HERZOG, M. Fundamentos empíricos para uma teoria da mudança linguística. Trad. de Marcos Bagno. São Paulo: parábola editorial, 2006 [1968].

\section{()(1) $\circledast \circledast$}

